\title{
Deformable devices with integrated functional nanomaterials for wearable electronics
}

\author{
Jaemin Kim ${ }^{1,2 \dagger}{ }^{+}$Jongsu Lee ${ }^{1,2 \dagger}$, Donghee Son ${ }^{1,2}$, Moon Kee Choi ${ }^{1,2}$ and Dae-Hyeong Kim ${ }^{1,2^{*}}$
}

\begin{abstract}
As the market and related industry for wearable electronics dramatically expands, there are continuous and strong demands for flexible and stretchable devices to be seamlessly integrated with soft and curvilinear human skin or clothes. However, the mechanical mismatch between the rigid conventional electronics and the soft human body causes many problems. Therefore, various prospective nanomaterials that possess a much lower flexural rigidity than their bulk counterparts have rapidly established themselves as promising electronic materials replacing rigid silicon and/or compound semiconductors in next-generation wearable devices. Many hybrid structures of multiple nanomaterials have been also developed to pursue both high performance and multifunctionality. Here, we provide an overview of state-of-the-art wearable devices based on one- or two-dimensional nanomaterials (e.g., carbon nanotubes, graphene, single-crystal silicon and oxide nanomembranes, organic nanomaterials and their hybrids) in combination with zero-dimensional functional nanomaterials (e.g., metal/oxide nanoparticles and quantum dots). Starting from an introduction of materials strategies, we describe device designs and the roles of individual ones in integrated systems. Detailed application examples of wearable sensors/actuators, memories, energy devices, and displays are also presented.
\end{abstract}

Keywords: Silicon nanomembrane, Functional nanomaterials, Flexible electronics, Stretchable electronics, Wearable electronics

\section{Introduction}

In the rapid technology development of low-power silicon electronics, light-emitting diodes (LEDs) fabricated on unconventionally shaped substrates, high-capacity lithium-ion batteries, and various wearable electronic devices such as smart glasses, watches, and lenses have been unveiled both in academic journals and on the market. In spite of their superb performance, wearable form factors, and compact sizes, challenges remain mainly owing to their large thickness and mechanical rigidity, which result in a mechanical mismatch between the device and the skin, and thereby discomfort, a low signal-to-noise ratio, and measurement errors [1]. In this

\footnotetext{
*Correspondence: dkim98@snu.ac.kr

${ }^{\dagger}$ Jaemin Kim and Jongsu Lee contributed equally to this work

${ }^{2}$ School of Chemical and Biological Engineering, Institute of Chemical Processes, Seoul National University, Seoul 151-742, Republic of Korea Full list of author information is available at the end of the article
}

regard, achieving mechanical deformability of the wearable electronic/optoelectronic devices while maintaining high performances has been a major research goal [2-6].

One promising strategy is to replace the rigid electronic materials (e.g., silicon wafer) with flexible nanomaterials (e.g., silicon nanomembrane (SiNM) [7-11], carbon nanotubes (CNTs) [12-14], graphene (GP) [1, $15,16]$, and organic nanomaterials $[17,18])$. The electronic properties of the SiNM (down to tens of nanometers) remain the same as the bulk silicon wafer [19], but its bendability dramatically increases owing to the reduced thickness [5]. SiNM-based devices outperform their competitors including low-temperature polycrystalline silicon (LTPS) and organic devices by virtue of their high electron mobility [20]. However, SiNM based device might have issues in the high cost and complicated fabrication processes. Meanwhile, carbon nanomaterials (e.g., CNTs and GP) [21, 22] have been getting

\section{Springer}

(c) 2016 Kim et al. This article is distributed under the terms of the Creative Commons Attribution 4.0 International License (http:// creativecommons.org/licenses/by/4.0/), which permits unrestricted use, distribution, and reproduction in any medium, provided you give appropriate credit to the original author(s) and the source, provide a link to the Creative Commons license, and indicate if changes were made. 
attentions as next-generation semiconducting nanomaterials. The mobility of single-walled CNTs (SWNTs) and exfoliated GP have been reported up to 100,000 [21] and $230,000 \mathrm{~cm}^{2} \mathrm{~V}^{-1} \mathrm{~s}^{-1}$ [22], respectively, which are higher than that of single-crystal silicon. Their ultrathin thickness enables them to be seamlessly integrated in wearable devices while achieving the transparency [23-25]. The mass production, device performance, and fabrication processes of these carbon nanomaterials, however, have many remaining challenges for commercial device applications [26]. Organic nanomaterials such as organic nanowires/nanofibers also have recently utilized as electric materials for fabricating complementary metal-oxide-semiconductor (CMOS) circuits [27] and wearable power generators $[28,29]$. Intrinsic deformability of organic nanomaterials, solution processability, and low cost make them promising for wearable devices [27]. However, their low electrical performances should be resolved for its widespread applications [17].

Another approach to achieve both high performance and multifunctionality is to utilize hybrids of nanomaterials [30-36]. Functional hybrid nanomaterials often exhibit substantially different physical, mechanical, magnetic, chemical, and optical properties compared to their individual and/or bulk counterparts [37-40]. By integrating different functional nanomaterials, the performance of wearable devices can be dramatically improved and/or diversified $[1,7,41-46]$. For the realization of this goal, the type, size, thickness, and concentration of the nanomaterials should be carefully designed [46]. In the following, we summarize recently reported wearable sensors/ actuators [7, 13, 47], memories [41, 48], energy storage devices [49], and displays [50, 51] that exploit various nanomaterials $[7,44,46,52,53]$ and their hybrids (Fig. 1). We also describe the roles of each nanomaterial in specific devices, improved device functions, their system integrations, and provide brief perspectives on future research directions.

\section{Review}

\subsection{Wearable sensors/actuators}

Wearable sensors/actuators have recently attracted considerable interest because of their mobile healthcare [54] and virtual reality applications [55]. Sensors/actuators worn on the body, in particular, have drawn attention for the continuous and accurate monitoring of physiological (e.g., motion [1, 47] and temperature [56, 57]) and electrophysiological (e.g., electrocardiograms [58, 59] and electromyograms $[60,61])$ signals and appropriate instant feedback on them [1], which are important for point-of-care medical diagnostics and therapy. This section describes representative wearable sensors/actuators based on functional nanomaterials and their application examples in healthcare and human-machine interfaces.

\subsubsection{SiNM-based sensors}

Deformability, which is one of the key characteristics of wearable electronics, can be achieved by making inorganic materials (i.e., silicon) as thin as possible, down to the nanometer scale (i.e., nanomembrane) [5]. SiNM can be fabricated through several processes. One easy fabrication method is to remove the buried oxide of a silicon-on-insulator (SOI) wafer and pick the top part up or to etch the bottom silicon of the SOI wafer and use the remaining top part [7]. The obtained SiNM can be located in the desired position of the designed layout by using previously reported transfer printing techniques. SiNM maintains the high carrier mobility [20] and intrinsic piezoresistivity [7] of the bulk monocrystalline silicon, while having a high flexibility, which enables diverse wearable electronics applications.

For instance, multiplexing through SiNM transistors integrated into the flexible high-density electrode array achieves the real-time analysis of electrophysiological signals over a large area of the brain [10] and heart [62] surface. SiNM strain gauges integrated onto polymeric substrates are applied as wearable motion sensors thanks to their high piezoresistive sensitivity $[7,8]$. Figure 2a shows images of a SiNM strain gauge array integrated with a finger tube that conforms to the thumb. The bending motion of the thumb applies a tensile stress to the SiNM strain gauges, and their resistance increases accordingly without any hysteresis (Fig. 2b). Multiplexing by SiNM $\mathrm{p}-\mathrm{i}-\mathrm{n}$ junction diodes is also advantageous for constructing a wearable high-spatial-resolution temperature sensor array. Figure $2 \mathrm{c}$ depicts an $8 \times 8 \mathrm{p}-\mathrm{i}-\mathrm{n}$ junction diode array located on a heated $\mathrm{Cu}$ element (left) and its measured temperature distribution (right). The rectifying characteristics of silicon diodes enable each cell to be individually addressable with the minimum number of wires and crosstalk, achieving a high spatial resolution. The ultrathin dimensions of the sensor array facilitate not only conformal contacts with the target surface but also a fast response time by virtue of its extremely low thermal mass.

By combining the SiNM strain gauge, pressure sensor, and temperature sensor array in a single platform, a skinlike device conformally mounted onto a prosthetic arm is demonstrated. The SiNM strain gauge array monitors the change in the strain distribution according to the clenching motion of the prosthetic hand (Fig. 2d). Similarly, the SiNM pressure sensor measures the applied pressure when typing with a keyboard (Fig. 2e, top) and grasping a baseball (Fig. 2e, bottom). The SiNM temperature sensor 


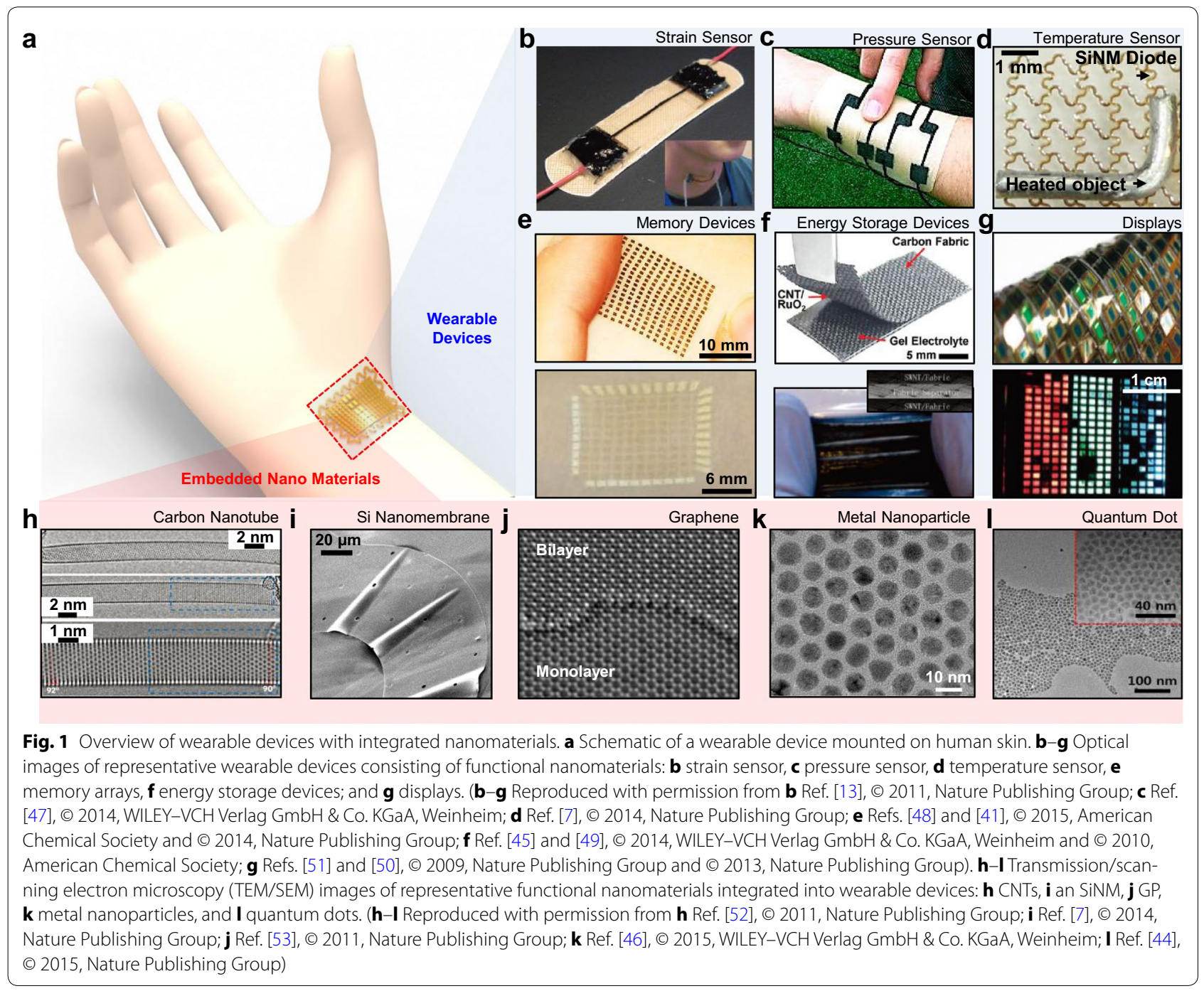

mounted on the prosthetic skin distinguishes different surface temperatures (Fig. 2f). Although these SiNM sensors exhibit a high potential for various wearable sensing applications, there are cost issues to be addressed for the development of commercial products.

\subsubsection{CNT-based wearable sensors}

The macroscopic form of CNTs in most devices is either their aligned arrays or random networks. Hata et al. [12] developed a synthesis method for ultra-long vertically aligned CNTs using the water-assisted chemical vapor deposition (CVD) process. The vertically aligned CNTs could be selectively grown on a patterned catalyst layer and transferred onto a stretchable substrate for device applications such as a strain sensor (Fig. 3a) [13]. In this strain measurement, the CNT film deforms as the substrate is stretched and its resistance increases. This relative change in the resistance according to the applied strain can be used for human-motion detection. When the sensor is attached to a human knee, the change in the resistance exhibits variations corresponding to the wearer's motion (Fig. 3b). Although vertical CNTs are densely aligned similar to a forest and therefore have a dark color, randomly oriented CNT networks are relatively transparent, particularly at reduced CNT concentrations [14]. Figure 3c shows a schematic of a transparent patch-type strain sensor using random-network CNTs integrated with a conducting polymer. By virtue of its optical transparency (62\%), it was inconspicuously patched onto a human face and successfully distinguished facial motions (Fig. 3d-f).

CNTs are also excellent nanoscale filler materials owing to their small size with good dispersion and exceptional electrical and physical properties [63, 64]. In this 


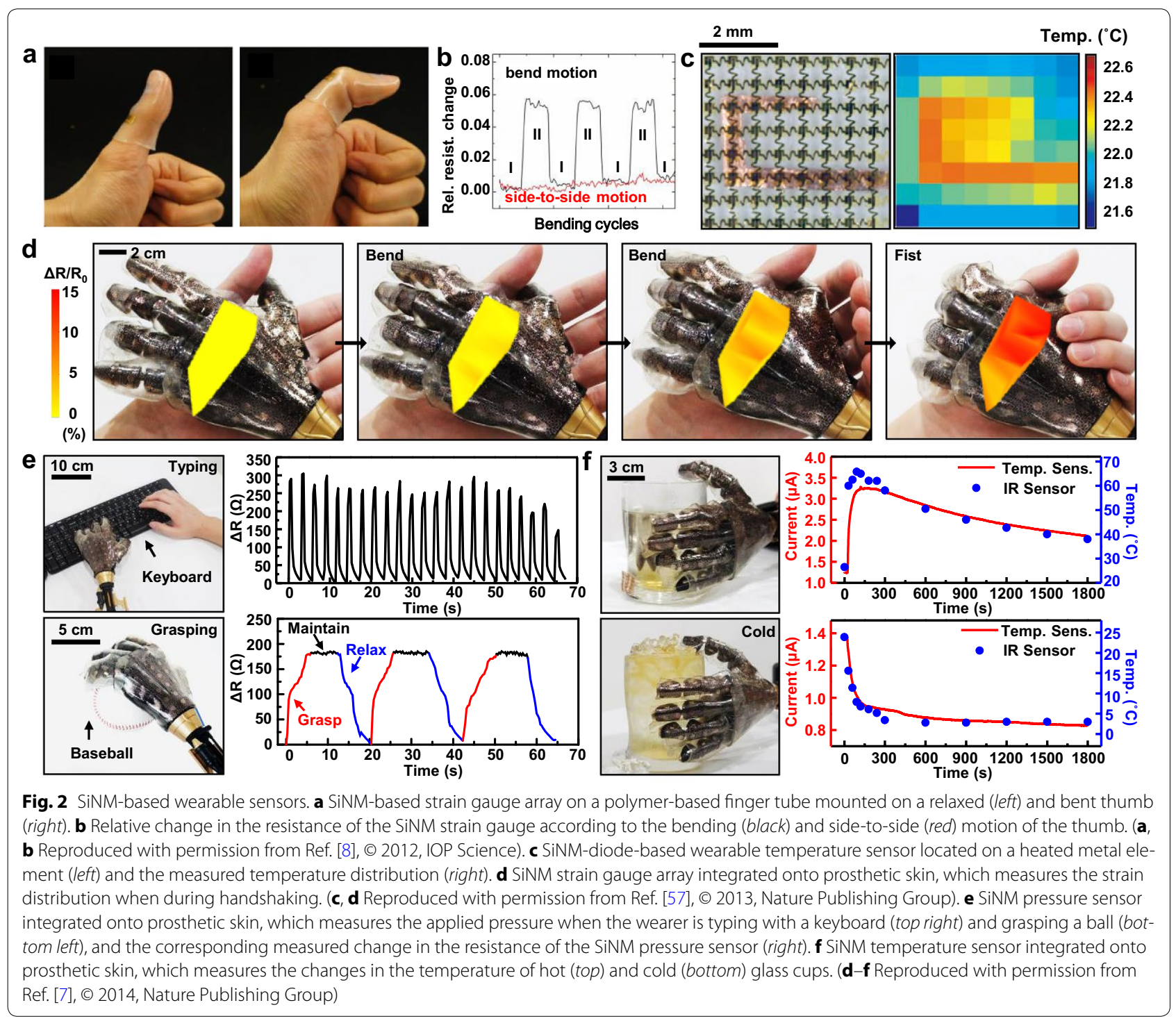

regard, electrically conductive rubber (ECR), which is a composite of CNTs and elastomeric polymers, is prepared and used for a wearable mechanical sensor [47]. To enhance the sensitivity, nanopores and micropores are introduced into the ECR, thereby increasing its piezoresistivity and maximizing the locally induced strain when deformed [47]. Figure $3 \mathrm{~g}$ shows a representative method for introducing pores with a uniform size and distribution in the ECR. The key idea of this method is to use a reverse micelle solution (RMS) comprising an emulsifier, deionized (DI) water, and an organic solvent. In accordance with careful sequential heat treatments, the migration and merging of the reverse micelles and subsequent pore generations occur (Fig. 3h). A larger porosity and lower elastic modulus are achieved if a larger amount of solvent is included in the RMS, thereby resulting in a higher pressure sensitivity (Fig. 3i). An ECR-based strain gauge fabricated on a medical bandage by using ink-jet printing forms a conformal contact with the human wrist and successfully monitors wrist motions. Although sensors based on CNT networks/composites are relatively cheap, especially those that are solution-processed, and mechanically compatible when worn on the human body, several issues such as a slow response time, a large area uniformity, and the hysteresis and drift of signals still need to be solved.

\subsubsection{Wearable sensors/actuators based on nanomaterial hybrids}

In several cases, electronic materials having a relatively poor performance are incorporated owing to the limited processing temperature and chemical/mechanical 


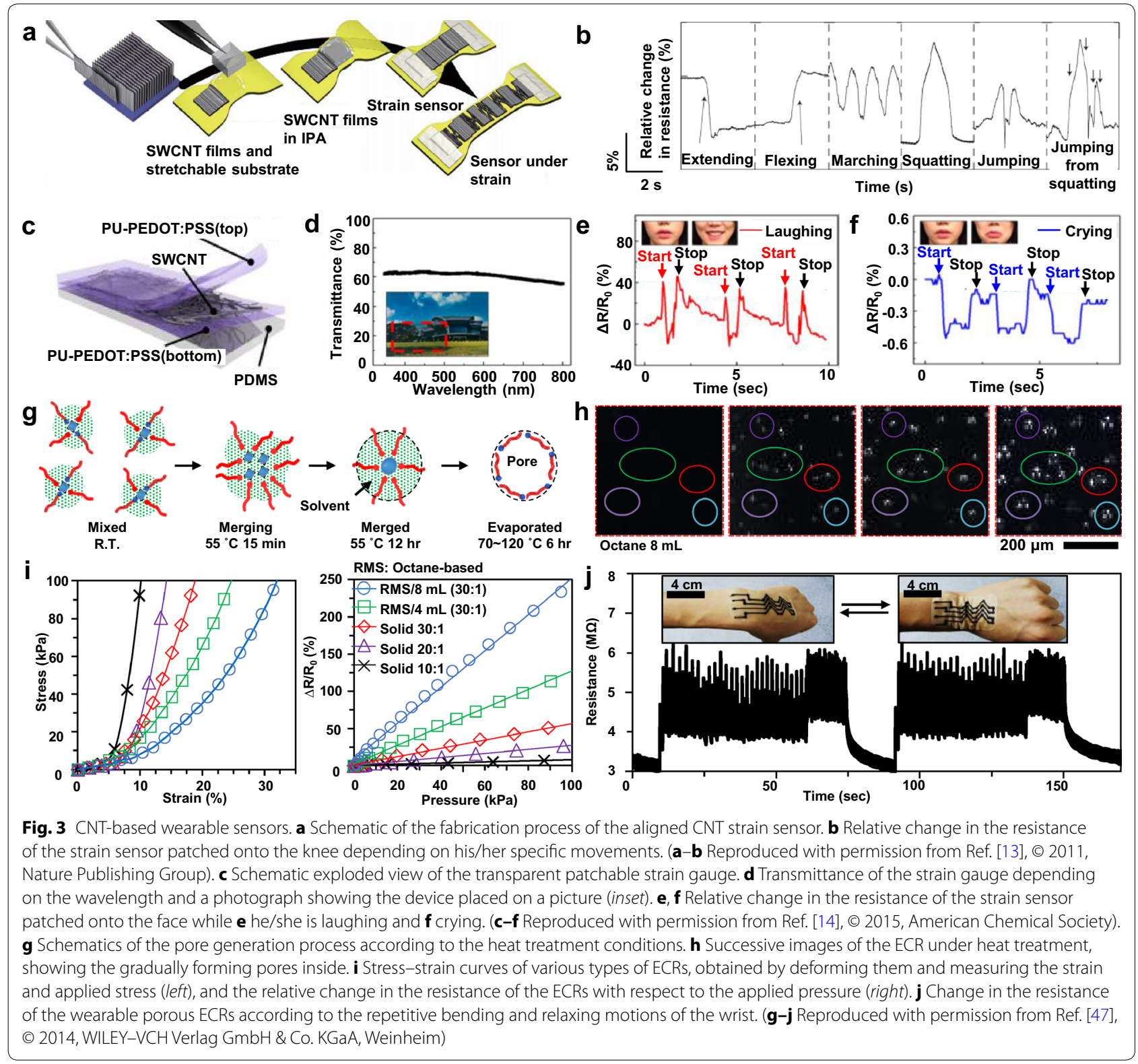

resistance of plastic substrates [65]. Appropriately chosen functional nanomaterials compensate for these limitations and improve the device performance [46, 66]. Figure 4a shows a transparent piezoelectric motion sensor and electrotactile stimulator (inset) conformally laminated onto the human skin. The piezoelectric motion sensor consists of GP layers as the transparent electrodes, polylactic acid (PLA) as the piezoelectric material, and SWNTs as the piezoelectric performance enhancer (Fig. 4b, left). Moreover, the electrotactile stimulator utilizes doped GP layers as transparent electrodes and silver nanowires (AgNWs) as a conductivity enhancer (Fig. 4b, right). The strain-induced charge separation in PLA is the main mechanism for piezoelectric energy generation. The local increase in the modulus by the CNTs increases the locally induced strain inside PLA under deformation, which maximizes charge generation (Fig. 4c). Figure 4d shows the conductivity enhancement by AgNWs sandwiched between GP layers. The enhanced conductivity of the GP/AgNWs/GP hybrid contributes to effective electrotactile stimulation (Fig. 4e).

Figure $4 \mathrm{f}$ shows an illustration and optical image (inset) of a semitransparent piezoelectric strain sensor and resistive temperature sensor for measuring wrist motions and body-temperature changes for wheelchair control and hypothermia diagnosis, respectively. The 


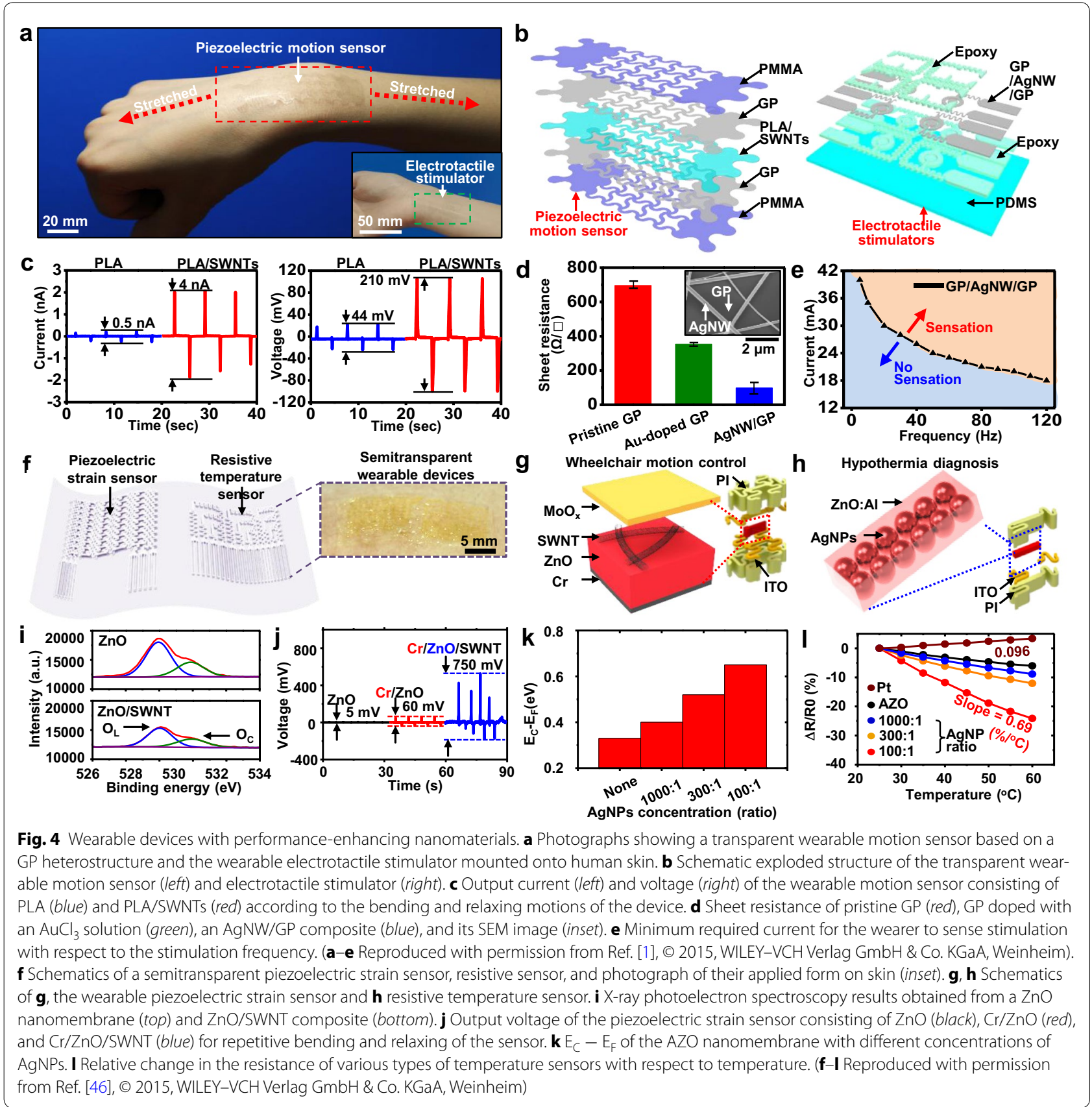

strain sensor consists of a $\mathrm{ZnO}$ nanomembrane as the piezoelectric material and SWNT networks as the performance enhancer (Fig. 4g). The temperature sensor consists of silver nanoparticles (AgNPs) embedded in the $\mathrm{ZnO}: \mathrm{Al}$ (AZO) nanomembrane for improving its sensitivity (Fig. 4h). For the strain sensor, co-deposited $\mathrm{Cr}$ and SWNTs layers improve the crystallinity of $\mathrm{ZnO}$ and passivate intrinsic defects, respectively (Fig. 4i). These modifications dramatically amplify the piezoelectric voltage output of the intrinsic $\mathrm{ZnO}$ nanomembrane (Fig. 4j). For the temperature sensor, $E_{C}-E_{F}\left(E_{C}\right.$, minimum energy of the conduction band; $E_{F}$, Fermi energy level) is proportional to the concentration of AgNPs inside the $\mathrm{ZnO}$ nanomembrane (Fig. 4k). The high concentration of AgNPs increases the carrier density and therefore improves the sensitivity of the temperature sensor (Fig. 4l). A more in-depth study of functional hybrid nanomaterials would provide new opportunities for high-performance wearable devices. 


\subsection{Wearable memories}

Data recorded by wearable sensors should be either transferred or stored for the analysis. Usually, the data are stored in memory devices and retrieved when needed. In this section, two types of ultrathin deformable nonvolatile memory devices-charge-trap floating-gate memory (CTFM) [48] and resistive random access memory (RRAM) [41]-are described.

\subsubsection{Deformable charge-trap floating-gate memory}

Since the concept of memory devices using floating gates was first proposed [67], field-effect transistor (FET)based CTFM has established itself as a dominant data storage device owing to its small area and compatibility with the CMOS process $[68,69]$. For the realization of deformable CTFMs as next-generation devices, the rigid active materials are replaced with deformable ones such as organic materials [70,71], SWNTs [48], 2D nanomembranes [72], and even inorganic SiNMs [73]. Figure 5a and b show the device structure of an SWNT-based CTFM and its laminated form on the human skin, respectively. The Au nanomembrane as a floating gate maximizes the charge capturing functionality (Fig. 5c). Soft active layers of SWNT networks are located at the neutral mechanical plane and allow stable operation under deformation.

The floating gate of a continuous metal film has a critical limitation for the retention time [74]. Instead, metal nanoparticles (NPs) are a promising candidate as the floating gate to realize a fast program/erase speed and long retention time [74]. Figure 5e shows an optical image of a fabricated flexible CTFM using poly(4-vinylphenol) (PVP), pentacene, and gold nanoparticles (AuNPs) as the dielectric, semiconductor, and charge-trap layer, respectively. AuNPs are electrostatically adsorbed onto the PVP blocking oxide, thereby forming a monolayer of AuNPs (Fig. 5f). A large on/off window $(>10 \mathrm{~V})$ is obtained owing to the high density of AuNPs (Fig. 5g). Repetitive bending up to 1000 cycles with a bending radius of $20 \mathrm{~mm}$ does not diminish the performance of the CTFM.

\subsubsection{Nanoparticle-embedded wearable RRAM}

RRAM is another promising candidate for future nonvolatile memory devices [75-77]. By integrating RRAM with wearable sensors, a low power consumption and mechanical deformability are important for long-term use in mobile environments [41]. Figure 5i shows wearable RRAM consisting of AuNP charge-trap layers that reduce its operation current. Serpentine interconnections make the wearable RRAM stretchable up to $25 \%$ strain (Fig. 5j-l). AuNPs embedded between $\mathrm{TiO}_{2}$ nanomembranes by Langmuir-Blodgett assembly form a uniform layer over a large area (Fig. $5 \mathrm{~m}-\mathrm{o}$ ). The operation current of the wearable RRAM with one AuNP layer is decreased by one order of magnitude compared to that without AuNPs (Fig. 5p). Three layers of AuNPs exhibit a larger current decrease (by almost a factor of three).

\subsection{Wearable displays}

To construct user-interactive wearable electronic systems, deformable displays that visualize measured or stored data are indispensable for users. Recently, several breakthroughs in deformable LED technologies, including deformable inorganic/organic LEDs [51, 78-81], polymer LEDs [82-84], and quantum-dot LEDs (QLEDs) [85-87], have been reported.

Figure $6 \mathrm{a}-\mathrm{c}$ show an image of a deformable actively multiplexed organic LED array, the device structure, and the bending capability, respectively. However, organic light-emitting materials have a low stability in air and a low photostability, and thus they need thick encapsulation under ambient conditions. Quantum dots, on the other hand, have favorable properties such as a good stability in air, good photostability, printability on various substrates, and a high brightness at low operating voltages, which are important key factors for deformable/wearable displays $[88,89]$. Figure $6 \mathrm{~d}$ and e show the structure of recently reported wearable QLED devices [44]. Thanks to ultrathin active and encapsulation layers, the total thickness of the device is $\sim 2.6 \mu \mathrm{m}$, enabling conformal contact with the wearer's skin. The wearable QLED is turned on at a low voltage (2 V; Fig. 6j) and endures $20 \%$ stretching up to 1000 cycles without any degradation in its brightness (Fig. 6g). The use of biocompatible quantum dots and the replacement of the rigid transparent electrodes with soft ones further improve the practical applications of wearable QLEDs.

\subsection{Wearable energy devices}

Energy storage devices and power generators that supply power to wearable electronics need flexibility and biocompatibility. An all-solid-state supercapacitor (SC) [45, $49,90,91]$ is a suitable energy storage device with regard to this point. Moreover, SCs have a high power density, a fast charging/discharging speed, and cycle durability [92]. In case of the wearable power generators, flexible and soft fiber-based materials are suitable owing to the requirement of high deformability [28]. In this section, carbon-nanomaterial-based flexible $\mathrm{SCs}$ and organic nanofiber-based power generators are reviewed.

\subsubsection{CNT-based wearable energy devices}

The excellent electrochemical properties, electrical conductivity, large surface area, and mechanical softness of CNTs make them apt for the electrodes and current collectors of wearable SCs [93]. Cui et al. dipped fabric into a CNT-dispersed ink to coat the fabric fibers with CNT 


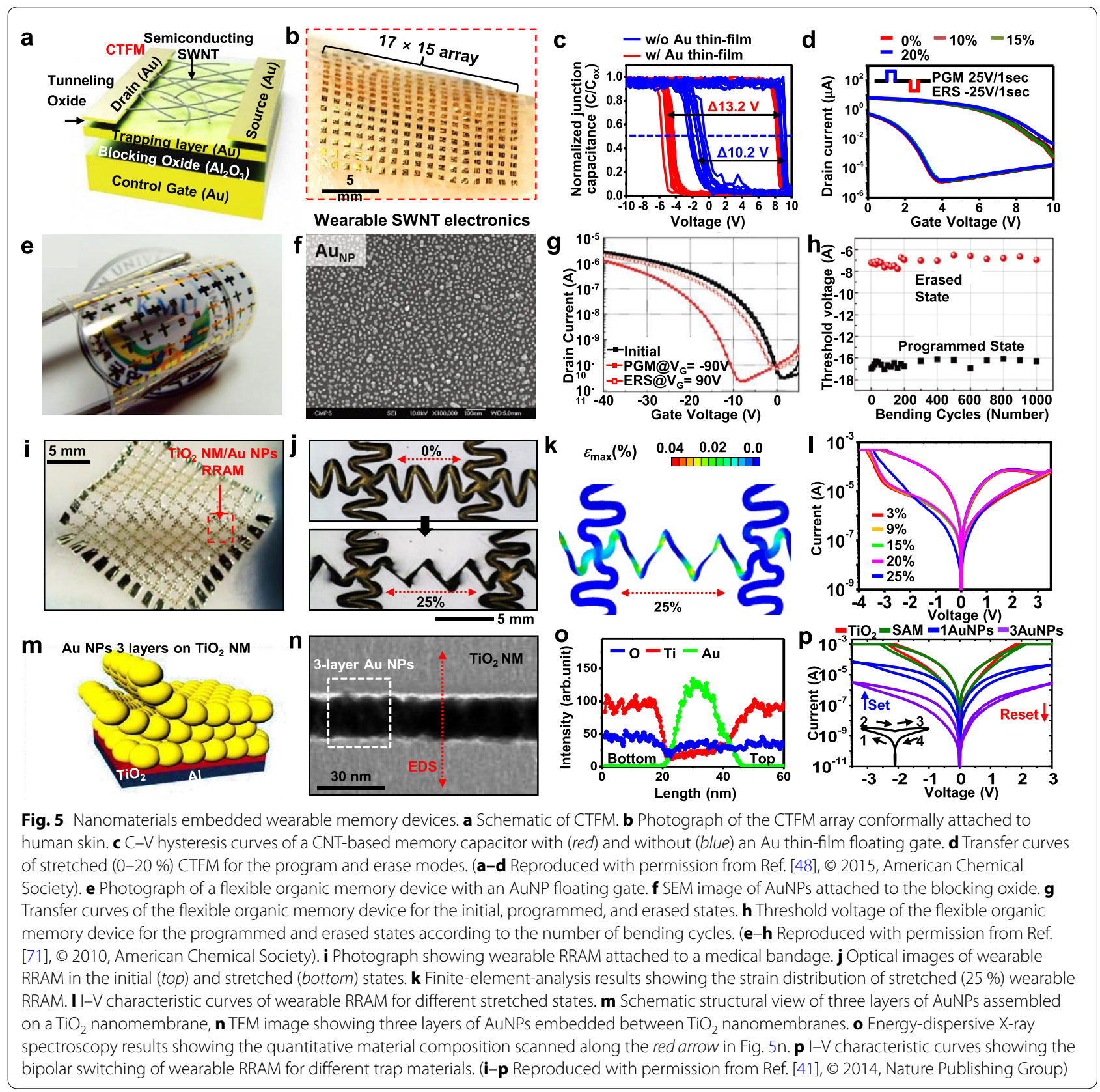

random networks (Fig. 7a, b) [49]. These engineered fabric electrodes assembled with a fabric separator in between form the SC (Fig. 7c). The large surface area of CNTs enables further decoration with other nanomaterials (e.g., pseudocapacitive metal oxide NPs such as $\mathrm{MnO}_{2}$ and $\mathrm{RuO}_{2}$ ) [94, 95]. The surface of the CNT fabric is electroplated with $\mathrm{MnO}_{2} \mathrm{NPs}$ (Fig. 7d, e), which increases the specific capacitance.

Instead of coating fabrics, carbon fibers are used to make a woven fabric, which can be applied to flexible textile electrodes [45]. To maximize the surface area, vertically-aligned CNTs are additionally synthesized on the carbon fabric. Electroplating vertical CNTs with $\mathrm{RuO}_{2}$ NPs further increases the capacitance (Fig. 7f), and an all-solid-state wearable $\mathrm{SC}$ is fabricated by sandwiching a poly(vinyl alcohol) (PVA)- $\mathrm{H}_{3} \mathrm{PO}_{4}$ gel electrolyte between two modified carbon fabric electrodes (Fig. 7g). The resulting SC exhibits high performance up to 135-degree bending and 4000 charge-discharge cycles (Fig. 7h-j).

\subsubsection{GP-based wearable energy devices}

Multiple chemically converted GP sheets are beneficial for fast ion transport [15]. GP flakes and/or reduced GP oxides are densely packed by capillary pressure 


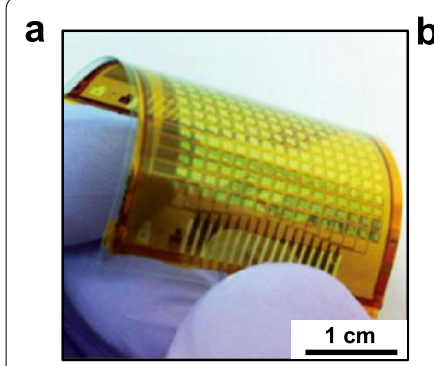

d

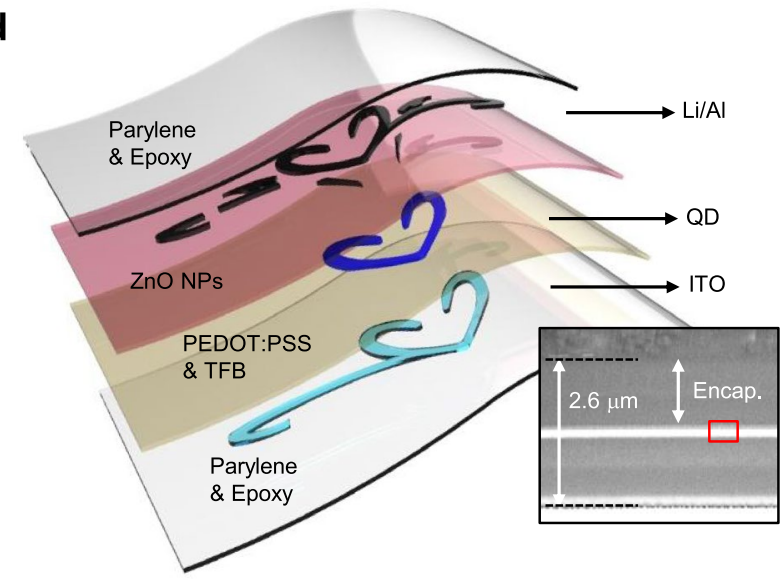

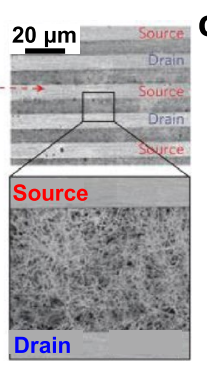
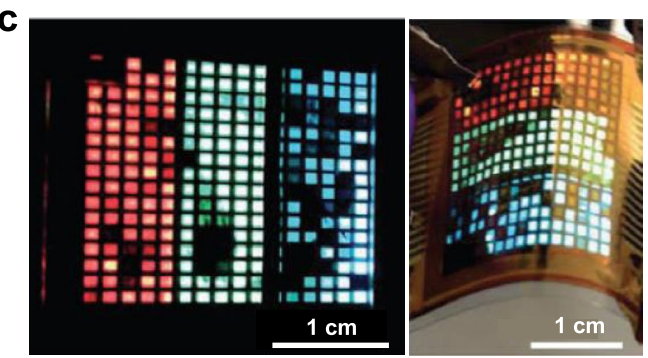

e
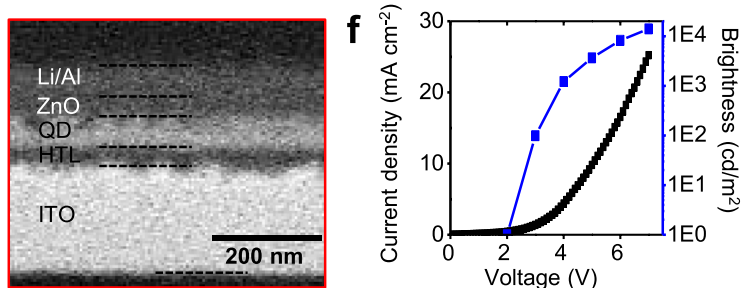

9

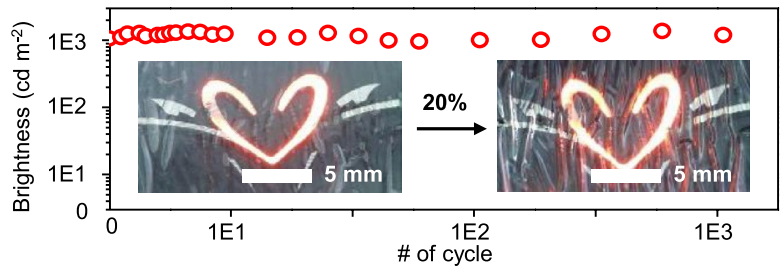

Fig. 6 Deformable displays. a Photograph of a fabricated flexible OLED display containing $16 \times 16$ pixels. b Optical image of one pixel of the flexible OLED (left) and an enlarged view of the multiplexing CNT FET (right). c, Full-color flexible OLED display in which all pixels are turned on (left) and its bent form (right). (a-c Reproduced with permission from Ref. [50], ( ) 2013, Nature Publishing Group). d Schematic exploded view showing the device structure of a wearable QLED and an SEM image showing the cross section of the display. $\mathbf{e}$ TEM image of the active layer indicated by the red box in the inset of $\mathbf{d}$. $\mathbf{f} J-V-L$ characteristic curves of the wearable QLED. $\mathbf{g}$ Stable brightness of the wearable QLED during repetitive stretching cycles. Insets show the initial and stretched states of the wearable QLED. (d- $\mathbf{g}$ Reproduced with permission from Ref. [44], @ 2015, Nature Publishing Group)

to fabricate flexible carbon electrodes (Fig. 7k). The packing density $(\rho)$ of the GP sheets can be controlled by changing the ratio of the volatile and nonvolatile liquids in the gel (Fig. 7l, m). Figure $7 \mathrm{n}$ and o show the specific capacitance and volumetric capacitance, respectively, of SCs using stacked GP electrodes for different values of $\rho$. The specific capacitance slightly decreases as $\rho$ increases, whereas the volumetric capacitance is nearly proportional to $\rho$. Although most SCs made of activated carbon exhibit a volumetric energy density of 5-8 Wh/L, SCs made of the GP assembly exhibit a volumetric energy density of $60 \mathrm{Wh} / \mathrm{L}$, which is similar to that of lead-acid batteries (50-90 Wh/L).

\subsubsection{Organic nanofiber-based wearable power generators}

To harvest electrical energy from body movements, piezoelectric nanogenerators (PENGs) and triboelectric nanogenerators (TENGs) have been used [28, 96]. Organic nanofibers such as polyvinylidene fluoride (PVDF) formed by using electrospinning processes have shown superb deformability as well as high piezoresistivity, facilitating its use in wearable applications $[18,28]$. Piezoelectric power generation using a single PVDF nanofiber [97], aligned multiple PVDF nanofibers $[98,99]$, and randomly distributed nanofiber networks [100] have been demonstrated. Parallel and series connection of PVDF nanofibers increase the generated voltage and current [98]. However, relatively low output power of PENGs has limited the application for wearable devices with high power consumption [28]. In contrast, TENGs have shown much higher output power than PENGs [28]. Electrospun PVDF nanofibers are also suitable for fabrication of the TENG because of their strong electronegativity and high porous morphology offering large contact area to increase the output power $[28,101]$. The PVDF nanofiber-based TENG has been recently demonstrated as wearable forms [28]. Seamless integration of the organic nanofiberbased wearable power generators with energy storage devices and control circuits is another important future research topic. 


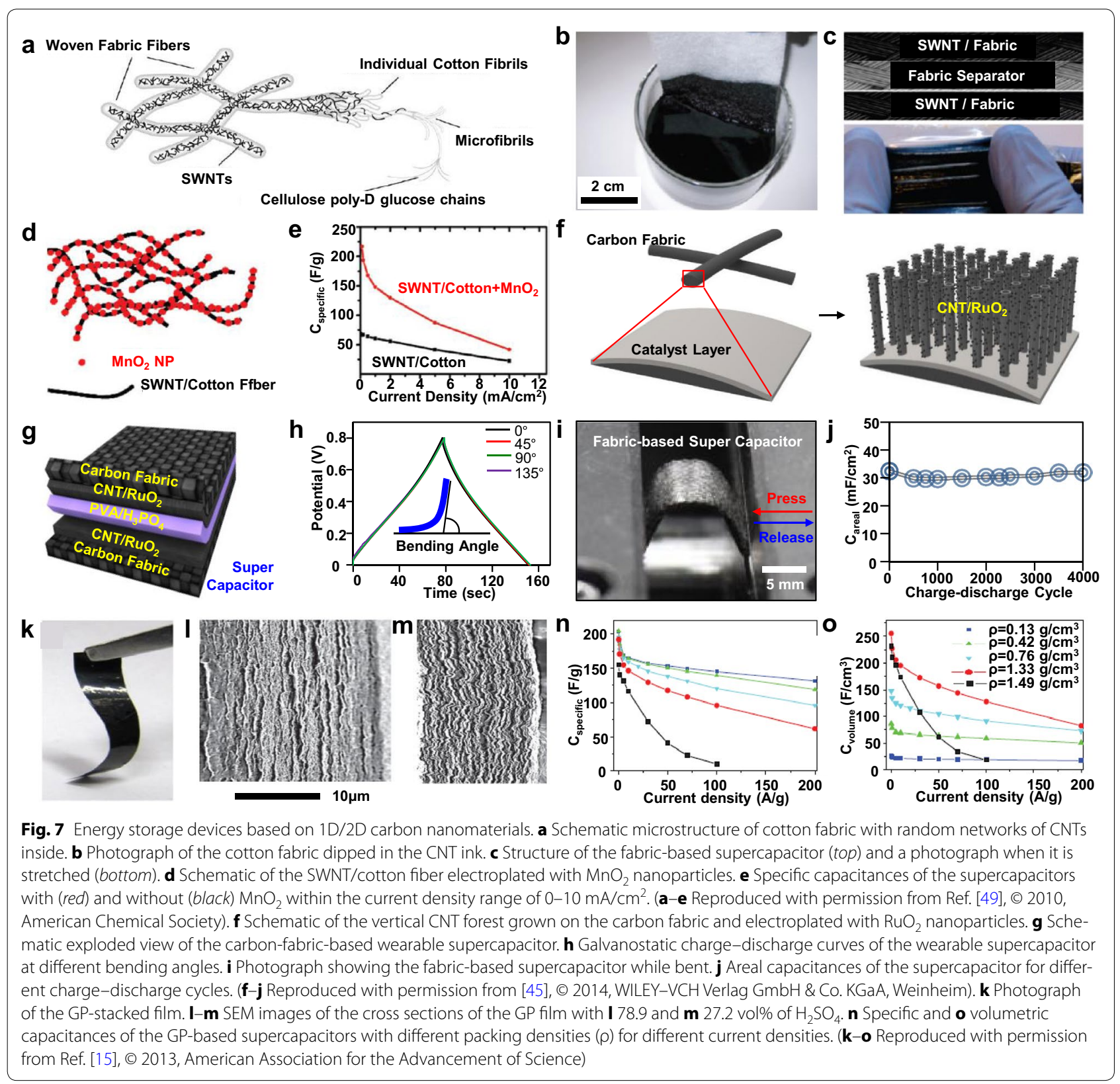

\section{Conclusions}

The mechanical, electrical, and optical properties of bulk materials change as their size is reduced and/ or nanoscale structure engineering is introduced. By using the unique properties of such nanomaterials or their hybrids, many breakthroughs in wearable devices have been accomplished. In this paper, we reviewed the current status of wearable devices including sensors/ actuators, memory devices, displays, and energy storage devices. We particularly focused on the use of functional nanomaterials to enhancing the deformability and performance of these devices. Continuous research and development of new nanomaterials/hybrids and their integration into variety of electronic/optoelectronic devices would provide new opportunities for next-generation wearable electronics.

\section{Authors' contributions}

JK and JL contributed equally. JK, JL, and D-HK wrote the manuscript. JK, JL, DS, MKC and D-HK designed the figures. All authors read and approved the final manuscript.

\section{Author details}

${ }^{1}$ Center for Nanoparticle Research, Institute for Basic Science (IBS), Seoul 151-742, Republic of Korea. ${ }^{2}$ School of Chemical and Biological Engineering, Institute of Chemical Processes, Seoul National University, Seoul 151-742, Republic of Korea. 


\section{Acknowledgements}

This research was supported by IBS-R006-D1. This work was supported by a Seoul National University Research Grant.

\section{Competing interests}

The authors declare that they have no competing interests.

Received: 6 August 2015 Accepted: 4 November 2015

Published online: 15 March 2016

\section{References}

1. S. Lim, D. Son, J. Kim, Y.B. Lee, J.K. Song, S. Choi, D.J. Lee, J.H. Kim, M. Lee, T. Hyeon, D.H. Kim, Transparent and stretchable interactive human machine interface based on patterned graphene heterostructures. Adv. Funct. Mater. 25, 375-383 (2015). doi:10.1002/adfm.201402987

2. J. Kim, M. Lee, J. Rhim, P. Wang, N. Lu, D.-H. Kim, Next-generation flexible neural and cardiac electrode arrays. Biomed. Eng. Lett. 4, 95-108 (2014). doi:10.1007/s13534-014-0132-4

3. D.H. Kim, J.H. Ahn, W.M. Choi, H.S. Kim, T.H. Kim, J.Z. Song, Y.G.Y. Huang, Z.J. Liu, C. Lu, J.A. Rogers, Stretchable and foldable silicon integrated circuits. Science 320, 507-511 (2008). doi:10.1126/science.1154367

4. D.H. Kim, R. Ghaffari, N.S. Lu, J.A. Rogers, Flexible and stretchable electronics for biointegrated devices. Annu. Rev. Biomed. Eng. 14, 113-128 (2012). doi:10.1146/annurev-bioeng-071811-150018

5. D.H. Kim, N.S. Lu, R. Ghaffari, J.A. Rogers, Inorganic semiconductor nanomaterials for flexible and stretchable bio-integrated electronics. NPG Asia Mater. 4, e15 (2012). doi:10.1038/am.2012.27

6. D.H. Kim, J.L. Xiao, J.Z. Song, Y.G. Huang, J.A. Rogers, Stretchable, curvilinear electronics based on inorganic materials. Adv. Mater. 22, 2108-2124 (2010). doi:10.1002/adma.200902927

7. J. Kim, M. Lee, H.J. Shim, R. Ghaffari, H.R. Cho, D. Son, Y.H. Jung, M. Soh, C. Choi, S. Jung, K. Chu, D. Jeon, S.T. Lee, J.H. Kim, S.H. Choi, T. Hyeon, D.H. Kim, Stretchable silicon nanoribbon electronics for skin prosthesis. Nat. Commun. 5, 5747 (2014). doi:10.1038/Ncomms6747

8. M. Ying, A.P. Bonifas, N.S. Lu, Y.W. Su, R. Li, H.Y. Cheng, A. Ameen, Y.G. Huang, J.A. Rogers, Silicon nanomembranes for fingertip electronics. Nanotechnology 23, 344004 (2012). doi:10.1088/0957-4484/23/34/344004

9. D.H. Kim, N.S. Lu, Y.G. Huang, J.A. Rogers, Materials for stretchable electronics in bioinspired and biointegrated devices. MRS Bull. 37, 226-235 (2012). doi:10.1557/mrs.2012.36

10. J. Viventi, D.H. Kim, L. Vigeland, E.S. Frechette, J.A. Blanco, Y.S. Kim, A.E. Avrin, V.R. Tiruvadi, S.W. Hwang, A.C. Vanleer, D.F. Wulsin, K. Davis, C.E. Gelber, L. Palmer, J. Van der Spiegel, J. Wu, J.L. Xiao, Y.G. Huang, D. Contreras, J.A. Rogers, B. Litt, Flexible, foldable, actively multiplexed, high-density electrode array for mapping brain activity in vivo. Nat. Neurosci. 14, 1599-1605 (2011). doi:10.1038/nn.2973

11. D.-H. Kim, W.M. Choi, J.-H. Ahn, H.-S. Kim, J. Song, Y. Huang, Z. Liu, C. Lu, C.G. Koh, J.A. Rogers, Complementary metal oxide silicon integrated circuits incorporating monolithically integrated stretchable wavy interconnects. Appl. Phys. Lett. 93, 044102 (2008). doi:10.1063/1.2963364

12. K. Hata, D.N. Futaba, K. Mizuno, T. Namai, M. Yumura, S. lijima, Waterassisted highly efficient synthesis of impurity-free single-waited carbon nanotubes. Science 306, 1362-1364 (2004). doi:10.1126/ science. 1104962

13. T. Yamada, Y. Hayamizu, Y. Yamamoto, Y. Yomogida, A. Izadi-Najafabadi, D.N. Futaba, K. Hata, A stretchable carbon nanotube strain sensor for human-motion detection. Nat. Nanotechnol. 6, 296-301 (2011). doi:10.1038/Nnano.2011.36

14. E. Roh, B.U. Hwang, D. Kim, B.Y. Kim, N.E. Lee, Stretchable, transparent, ultrasensitive, and patchable strain sensor for human-machine interfaces comprising a nanohybrid of carbon nanotubes and conductive elastomers. ACS Nano 9, 6252-6261 (2015). doi:10.1021/ acsnano. 5 b0 01613

15. X.W. Yang, C. Cheng, Y.F. Wang, L. Qiu, D. Li, Liquid-mediated dense integration of graphene materials for compact capacitive energy storage. Science 341, 534-537 (2013). doi:10.1126/science.1239089
16. S.M. Lee, J.H. Kim, J.H. Ahn, Graphene as a flexible electronic material: mechanical limitations by defect formation and efforts to overcome. Mater. Today 18, 336-344 (2015). doi:10.1016/j.mattod.2015.01.017

17. S.Y. Min, T.S. Kim, Y. Lee, H. Cho, W. Xu, T.W. Lee, Organic nanowire fabrication and device applications. Small 11,45-62 (2015). doi:10.1002/ smll.201401487

18. J.Y. Chang, M. Domnner, C. Chang, L.W. Lin, Piezoelectric nanofibers for energy scavenging applications. Nano Energy 1, 356-371 (2012). doi:10.1016/j.nanoen.2012.02.003

19. H. Jang, W. Lee, S.M. Won, S.Y. Ryu, D. Lee, J.B. Koo, S.D. Ahn, C.W. Yang, M.H. Jo, J.H. Cho, J.A. Rogers, J.H. Ahn, Quantum confinement effects in transferrable silicon nanomembranes and their applications on unusual substrates. Nano Lett. 13, 5600-5607 (2013). doi:10.1021/nl403251e

20. D.H. Kim, J.H. Ahn, H.S. Kim, K.J. Lee, T.H. Kim, C.J. Yu, R.G. Nuzzo, J.A. Rogers, Complementary logic gates and ring oscillators on plastic substrates by use of printed ribbons of single-crystalline silicon. IEEE Electron Device Lett. 29, 73-76 (2008). doi:10.1109/Led.2007.910770

21. T. Durkop, S.A. Getty, E. Cobas, M.S. Fuhrer, Extraordinary mobility in semiconducting carbon nanotubes. Nano Lett. 4, 35-39 (2004). doi:10.1021/nl034841q

22. K.I. Bolotin, K.J. Sikes, Z. Jiang, M. Klima, G. Fudenberg, J. Hone, P. Kim, H.L. Stormer, Ultrahigh electron mobility in suspended graphene. Solid State Commun. 146, 351-355 (2008). doi:10.1016/j.ssc.2008.02.024

23. E. Artukovic, M. Kaempgen, D.S. Hecht, S. Roth, G. GrUner, Transparent and flexible carbon nanotube transistors. Nano Lett. 5, 757-760 (2005) doi:10.1021/nl0505254o

24. L.B. Hu, W. Yuan, P. Brochu, G. Gruner, Q.B. Pei, Highly stretchable, conductive, and transparent nanotube thin films. Appl. Phys. Lett. 94, 161108 (2009). doi:10.1063/1.3114463

25. R.R. Nair, P. Blake, A.N. Grigorenko, K.S. Novoselov, T.J. Booth, T. Stauber, N.M.R. Peres, A.K. Geim, Fine structure constant defines visual transparency of graphene. Science 320, 1308 (2008). doi:10.1126/ science.1156965

26. M.F.L. De Volder, S.H. Tawfick, R.H. Baughman, A.J. Hart, Carbon nanotubes: present and future commercial applications. Science $\mathbf{3 3 9}$, 535-539 (2013). doi:10.1126/science.1222453

27. S.Y. Min, T.S. Kim, B.J. Kim, H. Cho, Y.Y. Noh, H. Yang, J.H. Cho, T.W. Lee, Large-scale organic nanowire lithography and electronics. Nat. Commun. 4, 1773 (2013). doi:10.1038/ncomms2785

28. T. Huang, C. Wang, H. Yu, H.Z. Wang, Q.H. Zhang, M.F. Zhu, Human walking-driven wearable all-fiber triboelectric nanogenerator containing electrospun polyvinylidene fluoride piezoelectric nanofibers. Nano Energy 14, 226-235 (2015). doi:10.1016/j.nanoen.2015.01.038

29. A. Gheibi, M. Latifi, A.A. Merati, R. Bagherzadeh, Piezoelectric electrospun nanofibrous materials for self-powering wearable electronic textiles applications. J. Polym. Res. 21, 469 (2014). doi:10.1007/ s10965-014-0469-5

30. X. Huang, C.L. Tan, Z.Y. Yin, H. Zhang, 25th anniversary article: hybrid nanostructures based on two-dimensional nanomaterials. Adv. Mater. 26, 2185-2204 (2014). doi:10.1002/adma.201304964

31. Z. Yan, L.L. Ma, Y. Zhu, I. Lahiri, M.G. Hahm, Z. Liu, S.B. Yang, C.S. Xiang, W. Lu, Z.W. Peng, Z.Z. Sun, C. Kittrell, J. Lou, W.B. Choi, P.M. Ajayan, J.M. Tour, Three-dimensional metal-graphene-nanotube multifunctional hybrid materials. ACS Nano 7, 58-64 (2013). doi:10.1021/nn3015882

32. L.P. Singh, K. Srivastava, R. Mishra, R.S. Ningthoujam, Multifunctional hybrid nanomaterials from water dispersible $\mathrm{CaF}_{2}: \mathrm{Eu}^{3+}, \mathrm{Mn}^{2+}$ and $\mathrm{Fe}_{3} \mathrm{O}_{4}$ for luminescence and hyperthermia application. J. Phys. Chem. C 118, 18087-18096 (2014). doi:10.1021/jp502825p

33. C.A. Strassert, M. Otter, R.Q. Albuquerque, A. Hone, Y. Vida, B. Maier, L. De Cola, Photoactive hybrid nanomaterial for targeting, labeling, and killing antibiotic-resistant bacteria. Angew. Chem. Int. Edit. 48, 7928-7931 (2009). doi:10.1002/anie.200902837

34. A. Fahmi, T. Pietsch, C. Mendoza, N. Cheval, Functional hybrid materials. Mater. Today 12, 44-50 (2009). doi:10.1016/S1369-7021(09)70159-2

35. D. Son, J. Lee, D.J. Lee, R. Ghaffari, S. Yun, S.J. Kim, J.E. Lee, H.R. Cho, S. Yoon, S.X. Yang, S. Lee, S.T. Qiao, D.S. Ling, S. Shin, J.K. Song, J. Kim, T. Kim, H. Lee, J. Kim, M. Soh, N. Lee, C.S. Hwang, S. Nam, N.S. Lu, T. Hyeon, S.H. Choi, D.H. Kim, Bioresorbable electronic stent integrated with therapeutic nanoparticles for endovascular diseases. ACS Nano 9, 5937-5946 (2015). doi:10.1021/acsnano.5b00651 
36. S.J. Kim, H.R. Cho, K.W. Cho, S.T. Qiao, J.S. Rhim, M. Soh, T. Kim, M.K. Choi, C. Choi, I. Park, N.S. Hwang, T. Hyeon, S.H. Choi, N.S. Lu, D.H. Kim, Multifunctional cell-culture platform for aligned cell sheet monitoring, transfer printing, and therapy. ACS Nano 9, 2677-2688 (2015). doi:10.1021/nn5064634

37. S.W. Zeng, D. Baillargeat, H.P. Ho, K.T. Yong, Nanomaterials enhanced surface plasmon resonance for biological and chemical sensing applications. Chem. Soc. Rev. 43, 3426-3452 (2014). doi:10.1039/c3cs60479a

38. C. Buzea, I.I. Pacheco, K. Robbie, Nanomaterials and nanoparticles: sources and toxicity. Biointerphases 2, MR17-172 (2007). doi:10.1116/1.2815690

39. T.J. Park, G.C. Papaefthymiou, A.J. Viescas, A. Moodenbaugh, S.S. Wong, Size-dependent magnetic properties of single-crystalline multiferroic $\mathrm{BiFeO}_{3}$ nanoparticles. Nano Lett. 7, 766-772 (2007). doi:10.1021/ nl063039w

40. D. Guo, G.X.Xie, J.B. Luo, Mechanical properties of nanoparticles: basics and applications. J. Phys. D Appl. Phys. 47, 013001 (2014). doi:10.1088/0022-3727/47/1/013001

41. D. Son, J. Lee, S. Qiao, R. Ghaffari, J. Kim, J.E. Lee, C. Song, S.J. Kim, D.J. Lee, S.W. Jun, S. Yang, M. Park, J. Shin, K. Do, M. Lee, K. Kang, C.S. Hwang, N.S. Lu, T. Hyeon, D.H. Kim, Multifunctional wearable devices for diagnosis and therapy of movement disorders. Nat. Nanotechnol. 9, 397-404 (2014). doi:10.1038/Nnano.2014.38

42. S. Choi, J. Park, W. Hyun, J. Kim, J. Kim, Y.B. Lee, C. Song, H.J. Hwang, J.H. Kim, T. Hyeon, D.H. Kim, Stretchable heater using ligand-exchanged silver nanowire nanocomposite for wearable articular thermotherapy. ACS Nano 9, 6626-6633 (2015). doi:10.1021/acsnano.5b02790

43. M.K. Choi, O.K. Park, C. Choi, S. Qiao, R. Ghaffari, J. Kim, D.J. Lee, M. Kim, W. Hyun, S.J. Kim, H.J. Hwang, S.-H. Kwon, T. Hyeon, N. Lu, D.-H. Kim, Cephalopod-inspired miniaturized suction cups for smart medical skin. Adv. Healthc. Mater. 5, 80-87 (2015). doi:10.1002/adhm.201500285

44. M.K. Choi, J. Yang, K. Kang, D.C. Kim, C. Choi, C. Park, S.J. Kim, S.I. Chae, T.H. Kim, J.H. Kim, T. Hyeon, D.H. Kim, Wearable red-green-blue quantum dot light-emitting diode array using high-resolution intaglio transfer printing. Nat. Commun. 6, 7149 (2015). doi:10.1038/ncomms8149

45. S. Jung, J. Lee, T. Hyeon, M. Lee, D.H. Kim, Fabric-based integrated energy devices for wearable activity monitors. Adv. Mater. 26 6329-6334 (2014). doi:10.1002/adma.201402439

46. M. Park, K. Do, J. Kim, D. Son, J.H. Koo, J. Park, J.-K. Song, J.H. Kim, M. Lee, T. Hyeon, D.-H. Kim, Oxide nanomembrane hybrids with enhanced mechano- and thermo-sensitivity for semitransparent epidermal electronics. Adv. Healthc. Mater. 4, 992-997 (2015). doi:10.1002/adhm.201500097

47. S. Jung, J.H. Kim, J. Kim, S. Choi, J. Lee, I. Park, T. Hyeon, D.H. Kim, Reverse-micelle-induced porous pressure-sensitive rubber for wearable human-machine interfaces. Adv. Mater. 26, 4825-4830 (2014). doi:10.1002/adma.201401364

48. D. Son, J.H. Koo, J.K. Song, J. Kim, M. Lee, H.J. Shim, M. Park, M. Lee, J.H. Kim, D.H. Kim, Stretchable carbon nanotube charge-trap floating-gate memory and logic devices for wearable electronics. ACS Nano 9 5585-5593 (2015). doi:10.1021/acsnano.5b01848

49. L. Hu, M. Pasta, F.L. Mantia, L. Cui, S. Jeong, H.D. Deshazer, J.W. Choi, S.M. Han, Y. Cui, Stretchable, porous, and conductive energy textiles. Nano Lett. 10, 708-714 (2010). doi:10.1021/nl903949m

50. C. Wang, D. Hwang, Z.B. Yu, K. Takei, J. Park, T. Chen, B.W. Ma, A. Javey, User-interactive electronic skin for instantaneous pressure visualization. Nat. Mater. 12, 899-904 (2013). doi:10.1038/nmat3711

51. T. Sekitani, H. Nakajima, H. Maeda, T. Fukushima, T. Aida, K. Hata, T. Someya, Stretchable active-matrix organic light-emitting diode display using printable elastic conductors. Nat. Mater. 8, 494-499 (2009). doi:10.1038/nmat2459

52. J.H. Warner, N.P. Young, A.I. Kirkland, G.A.D. Briggs, Resolving strain in carbon nanotubes at the atomic level. Nat. Mater. 10, 958-962 (2011). doi:10.1038/nmat3125

53. K.W. Urban, Electron microscopy the challenges of graphene. Nat. Mater. 10, 165-166 (2011). doi:10.1038/nmat2964

54. S. Patel, H. Park, P. Bonato, L. Chan, M. Rodgers, A review of wearable sensors and systems with application in rehabilitation. J. Neuroeng. Rehabil. 9, 21 (2012). doi:10.1186/1743-0003-9-21

55. B.A. Ponce, M.E. Menendez, L.O. Oladeji, C.T. Fryberger, P.K. Dantuluri, Emerging technology in surgical education: combining real-time augmented reality and wearable computing devices. Orthopedics 37 751-757 (2014). doi:10.3928/01477447-20141023-05

56. L. Gao, Y.H. Zhang, V. Malyarchuk, L. Jia, K.I. Jang, R.C. Webb, H.R. Fu, Y. Shi, G.Y. Zhou, L.K. Shi, D. Shah, X. Huang, B.X. Xu, C.J. Yu, Y.G. Huang, J.A. Rogers, Epidermal photonic devices for quantitative imaging of temperature and thermal transport characteristics of the skin. Nat. Commun. 5 4938 (2014). doi:10.1038/ncomms5938

57. R.C. Webb, A.P. Bonifas, A. Behnaz, Y.H. Zhang, K.J. Yu, H.Y. Cheng, M.X. Shi, Z.G. Bian, Z.J. Liu, Y.S. Kim, W.H. Yeo, J.S. Park, J.Z. Song, Y.H. Li, Y.G. Huang, A.M. Gorbach, J.A. Rogers, Ultrathin conformal devices for precise and continuous thermal characterization of human skin. Nat. Mater. 12, 938-944 (2013). doi:10.1038/nmat3755

58. W.H. Yeo, Y.S. Kim, J. Lee, A. Ameen, L.K. Shi, M. Li, S.D. Wang, R. Ma, S.H. Jin, Z. Kang, Y.G. Huang, J.A. Rogers, Multifunctional epidermal electronics printed directly onto the skin. Adv. Mater. 25, 2773-2778 (2013). doi:10.1002/adma.201204426

59. J.W. Jeong, M.K. Kim, H.Y. Cheng, W.H. Yeo, X. Huang, Y.H. Liu, Y.H. Zhang, Y.G. Huang, J.A. Rogers, Capacitive epidermal electronics for electrically safe, long-term electrophysiological measurements. Adv. Healthc. Mater. 3, 642-648 (2014). doi:10.1002/adhm.201300334

60. D.H. Kim, N.S. Lu, R. Ma, Y.S. Kim, R.H. Kim, S.D. Wang, J. Wu, S.M. Won, H. Tao, A. Islam, K.J. Yu, T.I. Kim, R. Chowdhury, M. Ying, L.Z. Xu, M. Li, H.J. Chung, H. Keum, M. McCormick, P. Liu, Y.W. Zhang, F.G. Omenetto, Y.G. Huang, T. Coleman, J.A. Rogers, Epidermal electronics. Science $\mathbf{3 3 3}$ 838-843 (2011). doi:10.1126/science.1206157

61. J.W. Jeong, W.H. Yeo, A. Akhtar, J.J.S. Norton, Y.J. Kwack, S. Li, S.Y. Jung, Y.W. Su, W. Lee, J. Xia, H.Y. Cheng, Y.G. Huang, W.S. Choi, T. Bretl, J.A. Rogers, Materials and optimized designs for human-machine interfaces via epidermal electronics. Adv. Mater. 25, 6839-6846 (2013). doi:10.1002/ adma.201301921

62. J. Viventi, D.H. Kim, J.D. Moss, Y.S. Kim, J.A. Blanco, N. Annetta, A. Hicks, J.L. Xiao, Y.G. Huang, D.J. Callans, J.A. Rogers, B. Litt, A conformal, bio-interfaced class of silicon electronics for mapping cardiac electrophysiology. Sci. Transl. Med. 2, 24ra22 (2010). doi:10.1126/ scitransImed.3000738

63. M. Moniruzzaman, K.I. Winey, Polymer nanocomposites containing carbon nanotubes. Macromolecules 39, 5194-5205 (2006). doi:10.1021/ ma060733p

64. B. Fiedler, F.H. Gojny, M.H.G. Wichmann, M.C.M. Nolte, K. Schulte, Fundamental aspects of nano-reinforced composites. Compos. Sci. Technol. 66, 3115-3125 (2006). doi:10.1016/j.compscitech.2005.01.014

65. B.K. Sharma, B. Jang, J.E. Lee, S.H. Bae, T.W. Kim, H.J. Lee, J.H. Kim, J.H. Ahn, Load-controlled roll transfer of oxide transistors for stretchable electronics. Adv. Funct. Mater. 23, 2024-2032 (2013). doi:10.1002/ adfm.201202519

66. H. Lee, Y. Lee, C. Song, H.R. Cho, R. Ghaffari, T.K. Choi, K.H. Kim, Y.B. Lee, D. Ling, H. Lee, S.J. Yu, S.H. Choi, T. Hyeon, D.H. Kim, An endoscope with integrated transparent bioelectronics and theranostic nanoparticles for colon cancer treatment. Nat. Commun. 6, 10059 (2015). doi:10.1038/ ncomms 10059

67. D. Kahng, S.M. Sze, A floating gate and its application to memory devices. Bell Sys. Tech. J. 46, 1288-1295 (1967)

68. J.S. Meena, S.M. Sze, U. Chand, T.Y. Tseng, Overview of emerging nonvolatile memory technologies. Nanoscale Res. Lett. 9, 526 (2014) doi:10.1186/1556-276x-9-526

69. R. Bez, E. Camerlenghi, A. Modelli, A. Visconti, Introduction to flash memory. Proc IEEE 91, 489-502 (2003). doi:10.1109/jproc.2003.811702

70. T. Sekitani, T. Yokota, U. Zschieschang, H. Klauk, S. Bauer, K. Takeuchi, M. Takamiya, T. Sakurai, T. Someya, Organic nonvolatile memory transistors for flexible sensor arrays. Science 326, 1516-1519 (2009). doi:10.1126/ science.1179963

71. S.-J. Kim, J.-S. Lee, Flexible organic transistor memory devices. Nano Lett. 10, 2884-2890 (2010). doi:10.1021/nl1009662

72. S.M. Kim, E.B. Song, S. Lee, J.F. Zhu, D.H. Seo, M. Mecklenburg, S. Seo, K.L. Wang, Transparent and flexible graphene charge-trap memory. ACS Nano 6, 7879-7884 (2012). doi:10.1021/nn302193q

73. J. Kim, D. Son, M. Lee, C. Song, J.-K. Song, J. H. Koo, D.J. Lee, H.J. Shim, J.H. Kim, M. Lee, T. Hyeon, D.H. Kim, A wearable multiplexed silicon nonvolatile memory array using nanocrystal charge confinement. Sci. Adv. 2, e1501101 (2016). doi:10.1126/sciadv.1501101 
74. J.-S. Lee, Recent progress in gold nanoparticle-based non-volatile memory devices. Gold Bull. 43, 189-199 (2010). doi:10.1007/BF03214986

75. R. Waser, M. Aono, Nanoionics-based resistive switching memories. Nat. Mater. 6, 833-840 (2007). doi:10.1038/nmat2023

76. D.H. Kwon, K.M. Kim, J.H. Jang, J.M. Jeon, M.H. Lee, G.H. Kim, X.S. Li, G.S. Park, B. Lee, S. Han, M. Kim, C.S. Hwang, Atomic structure of conducting nanofilaments in $\mathrm{TiO}_{2}$ resistive switching memory. Nat. Nanotechnol. 5, 148-153 (2010). doi:10.1038/Nnano.2009.456

77. J. Borghetti, G.S. Snider, P.J. Kuekes, J.J. Yang, D.R. Stewart, R.S. Williams, 'Memristive' switches enable 'stateful' logic operations via material implication. Nature 464, 873-876 (2010). doi:10.1038/nature08940

78. R.H. Kim, D.H. Kim, J.L. Xiao, B.H. Kim, S.I. Park, B. Panilaitis, R. Ghaffari, J.M. Yao, M. Li, Z.J. Liu, V. Malyarchuk, D.G. Kim, A.P. Le, R.G. Nuzzo, D.L. Kaplan, F.G. Omenetto, Y.G. Huang, Z. Kang, J.A. Rogers, Waterproof AllnGaP optoelectronics on stretchable substrates with applications in biomedicine and robotics. Nat. Mater. 9, 929-937 (2010). doi:10.1038/ nmat2879

79. T.I. Kim, J.G. McCall, Y.H. Jung, X. Huang, E.R. Siuda, Y.H. Li, J.Z. Song, Y.M. Song, H.A. Pao, R.H. Kim, C.F. Lu, S.D. Lee, I.S. Song, G. Shin, R. Al-Hasani, S. Kim, M.P. Tan, Y.G. Huang, F.G. Omenetto, J.A. Rogers, M.R. Bruchas, Injectable, cellular-scale optoelectronics with applications for wireless optogenetics. Science 340, 211-216 (2013). doi:10.1126/ science.1232437

80. S.I. Park, Y.J. Xiong, R.H. Kim, P. Elvikis, M. Meitl, D.H. Kim, J. Wu, J. Yoon, C.J. Yu, Z.J. Liu, Y.G. Huang, K. Hwang, P. Ferreira, X.L. Li, K. Choquette, J.A. Rogers, Printed assemblies of inorganic light-emitting diodes for deformable and semitransparent displays. Science 325, 977-981 (2009). doi:10.1126/science.1175690

81. T.H. Han, Y. Lee, M.R. Choi, S.H. Woo, S.H. Bae, B.H. Hong, J.H. Ahn, T.W. Lee, Extremely efficient flexible organic light-emitting diodes with modified graphene anode. Nat. Photon. 6, 105-110 (2012). doi:10.1038/ nphoton.2011.318

82. J.J. Liang, L. Li, X.F. Niu, Z.B. Yu, Q.B. Pei, Elastomeric polymer light-emitting devices and displays. Nat. Photon. 7, 817-824 (2013). doi:10.1038/ nphoton.2013.242

83. Z.B. Yu, X.F. Niu, Z.T. Liu, Q.B. Pei, Intrinsically stretchable polymer lightemitting devices using carbon nanotube-polymer composite electrodes. Adv. Mater. 23, 3989-3994 (2011). doi:10.1002/adma.201101986

84. M.S. White, M. Kaltenbrunner, E.D. Glowacki, K. Gutnichenko, G. Kettlgruber, I. Graz, S. Aazou, C. Ulbricht, D.A.M. Egbe, M.C. Miron, Z. Major, M.C. Scharber, T. Sekitani, T. Someya, S. Bauer, N.S. Sariciftci, Ultrathin, highly flexible and stretchable pleds. Nat. Photon. 7, 811-816 (2013). doi:10.1038/nphoton.2013.188

85. T.H. Kim, K.S. Cho, E.K. Lee, S.J. Lee, J. Chae, J.W. Kim, D.H. Kim, J.Y. Kwon, G. Amaratunga, S.Y. Lee, B.L. Choi, Y. Kuk, J.M. Kim, K. Kim, Full-colour quantum dot displays fabricated by transfer printing. Nat. Photon. $\mathbf{5}$ 176-182 (2011). doi:10.1038/nphoton.2011.12

86. X.Y. Yang, E. Mutlugun, C. Dang, K. Dev, Y. Gao, S.T. Tan, X.W. Sun, H.V. Demir, Highly flexible, electrically driven, top-emitting, quantum dot light-emitting stickers. ACS Nano 8, 8224-8231 (2014). doi:10.1021/ nn502588k

87. M.K. Choi, I. Park, D.C. Kim, E. Joh, O.K. Park, J. Kim, M. Kim, C. Choi, J. Yang, K.W. Cho, J.-H. Hwang, J.-M. Nam, T. Hyeon, J.H. Kim, D.-H. Kim, Thermally controlled, patterned graphene transfer printing for transparent and wearable electronic/optoelectronic system. Adv. Funct. Mater. 9, 7109-7118 (2015). doi:10.1002/adfm.201502956
88. J. Kwak, W.K. Bae, D. Lee, I. Park, J. Lim, M. Park, H. Cho, H. Woo, D.Y. Yoon, K. Char, S. Lee, C. Lee, Bright and efficient full-color colloidal quantum dot light-emitting diodes using an inverted device structure. Nano Lett. 12, 2362-2366 (2012). doi:10.1021/nl3003254

89. X.L. Dai, Z.X. Zhang, Y.Z. Jin, Y. Niu, H.J. Cao, X.Y. Liang, L.W. Chen, J.P. Wang, X.G. Peng, Solution-processed, high-performance light-emitting diodes based on quantum dots. Nature 515, 96-99 (2014). doi:10.1038/ nature13829

90. Y.J. Kang, S.J. Chun, S.S. Lee, B.Y. Kim, J.H. Kim, H. Chung, S.Y. Lee, W. Kim, All-solid-state flexible supercapacitors fabricated with bacterial nanocellulose papers, carbon nanotubes, and triblock-copolymer ion gels. ACS Nano 6, 6400-6406 (2012). doi:10.1021/nn301971r

91. X. Xiao, T.Q. Li, P.H. Yang, Y. Gao, H.Y. Jin, W.J. Ni, W.H. Zhan, X.H. Zhang, Y.Z. Cao, J.W. Zhong, L. Gong, W.C. Yen, W.J. Mai, J. Chen, K.F. Huo, Y.L. Chueh, Z.L. Wang, J. Zhou, Fiber-based all-solid-state flexible supercapacitors for self-powered systems. ACS Nano 6, 9200-9206 (2012). doi:10.1021/nn303530k

92. P. Simon, Y. Gogotsi, Materials for electrochemical capacitors. Nat. Mater. 7, 845-854 (2008). doi:10.1038/nmat2297

93. D.N. Futaba, K. Hata, T. Yamada, T. Hiraoka, Y. Hayamizu, Y. Kakudate, O. Tanaike, H. Hatori, M. Yumura, S. lijima, Shape-engineerable and highly densely packed single-walled carbon nanotubes and their application as super-capacitor electrodes. Nat. Mater. 5, 987-994 (2006). doi:10.1038/nmat1782

94. H. Zhang, G.P. Cao, Z.Y. Wang, Y.S. Yang, Z.J. Shi, Z.N. Gu, Growth of manganese oxide nanoflowers on vertically-aligned carbon nanotube arrays for high-rate electrochemical capacitive energy storage. Nano Lett. 8, 2664-2668 (2008). doi:10.1021/nl800925j

95. J.S. Ye, H.F. Cui, X. Liu, T.M. Lim, W.D. Zhang, F.S. Sheu, Preparation and characterization of aligned carbon nanotube-ruthenium oxide nanocomposites for supercapacitors. Small 1, 560-565 (2005). doi:10.1002/ smll.200400137

96. S. Jung, S. Hong, J. Kim, S. Lee, T. Hyeon, M. Lee, D.H. Kim, Wearable fall detector using integrated sensors and energy devices. Sci. Rep. 5 17081 (2015). doi:10.1038/srep17081

97. C.E. Chang, V.H. Tran, J.B. Wang, Y.K. Fuh, L.W. Lin, Direct-write piezoelectric polymeric nanogenerator with high energy conversion efficiency. Nano Lett. 10, 726-731 (2010). doi:10.1021/nl9040719

98. J. Chang, L. Lin, Large array electrospun PVDF nanogenerators on a flexible substrate. Paper presented at the 16th international conference on solid-state sensors, actuators and microsystems (TRANSDUCERS), Beijing, 5-9 June 2011

99. B.J. Hansen, Y. Liu, R.S. Yang, Z.L. Wang, Hybrid nanogenerator for concurrently harvesting biomechanical and biochemical energy. ACS Nano 4, 3647-3652 (2010). doi:10.1021/nn100845b

100. J. Fang, X.G. Wang, T. Lin, Electrical power generator from randomly oriented electrospun poly(vinylidene fluoride) nanofibre membranes. J. Mater. Chem. 21, 11088-11091 (2011). doi:10.1039/c1jm11445j

101. A.F. Diaz, R.M. Felix-Navarro, A semi-quantitative tribo-electric series for polymeric materials: the influence of chemical structure and properties. J. Electrostat. 62, 277-290 (2004). doi:10.1016/jelstat.2004.05.005

\section{Submit your manuscript to a SpringerOpen ${ }^{\odot}$ journal and benefit from:}

- Convenient online submission

- Rigorous peer review

- Immediate publication on acceptance

- Open access: articles freely available online

- High visibility within the field

- Retaining the copyright to your article

Submit your next manuscript at $>$ springeropen.com 